\title{
Flextensional Ultrasonic Piezoelectric Micro-Motor
}

\author{
Joni T. Leinvuo, Stephen A. Wilson, Roger W. Whatmore, and Markys G. Cain
}

\begin{abstract}
This paper presents the experimental design, construction, and operational characteristics of a new type of standing wave piezoelectric ultrasonic micro-motor. The motor uses a composite stator, consisting of a metallic flextensional mode converter, or "cymbal," bonded to a 2-mmsquare piezoelectric plate. The cymbal converts contourmode vibrations of the plate into oscillations in the cymbal, perpendicular to the stator plane. These are further converted into rotational movement in a rotor pressed against the cymbal by means of an elastic-fin friction drive to produce the required rotary actuation. The motor operates on a single-phase electrical supply, and direct control of the output speed and torque can be achieved by adjusting the amplitude and frequency of the supply voltage. Noncontact optical techniques were used to assess the performance of the developed micro-motor. The operational characteristics were developed from the acceleration and deceleration characteristics. No-load output speed $\left(11 \mathrm{rev} \mathrm{s}^{-1}\right)$ and stall torque $(27 \mathrm{nNm})$ were derived using high-speed imaging and image analysis. Maximum efficiency was $0.6 \%$.
\end{abstract}

\section{INTRODUCTION}

$\mathrm{P}$ IEZOELECTRIC ultrasonic motors [1] have a number of potential advantages. They maintain relatively high torque at relatively low speed without a reduction gear and exhibit a self-locking feature when electric power is turned off, because the driving mechanics use friction between the vibrating stator and the rotor. They are light compared with electromagnetic motors, and their equivalent inertias are low. They neither create electromagnetic fields nor are they affected by them. They also have many advantages for applications in microelectromechanical systems (MEMS) because, in contrast with electromagnetic motors, their simple construction makes them well suited for miniaturization, and their overall efficiency is relatively

Manuscript received November 24, 2005; accepted May 23, 2006. The authors gratefully acknowledge the partial financial support of the Engineering and Physical Sciences Research Council (EPSRC grant number GR/N 34017) and BAeSystems (Sowerby Research Center) in the development of the piezoelectric motor and the National Physical Laboratory in the development of the characterization system.

J. T. Leinvuo was with Cranfield University, Cranfield, Bedford, MK43 0AL, UK. He is presently with VTI Technologies Oy, Vantaa, Finland (e-mail: joni.leinvuo@vti.fi).

S. A. Wilson is with Cranfield University, Cranfield, Bedford, MK43 0AL, UK.

R. W. Whatmore was with Cranfield University, Cranfield, Bedford, MK43 0AL, UK. He is presently with Tyndall National Institute, Lee Maltings, Cork, Ireland.

M. G. Cain is with the National Physical Laboratory, Teddington, Middlesex, UK.

Digital Object Identifier 10.1109/TUFFC.2006.184 insensitive to size. In order to compare ultrasonic and electrostatic motors, it is important to consider energy densities $\left[\mathrm{J} / \mathrm{m}^{3}\right]$ of these two motor types. The maximum energy density for an electrostatic micro-motor is defined as $0.5 \varepsilon_{a i r} E_{b d}^{2}$, where $E_{b d}$ is the maximum electric field before breakdown $\left(\sim 10^{8} \mathrm{~V} / \mathrm{m}\right.$ for $1-\mu \mathrm{m}$ gaps $)$ and $\varepsilon_{\text {air }}$ is the permittivity of free space $\left(\varepsilon_{0}=8.854^{*} 10^{-12} \mathrm{Fm}^{-1}\right)$ [2]. For the piezoelectric motor, the energy density becomes $0.5 \varepsilon_{P Z T} E_{b d}^{2}$, where the electric field can be equivalent to that with an electrostatic motor. A three-magnitudeslarger dielectric constant $\left(\mathrm{PC} 4, \varepsilon_{P Z T}=1000 \varepsilon_{0}[3]\right)$ is possible with piezoelectric materials. The greater the energy density is, the greater potential there is to have higher torque outputs from the motor. Several micro-motor designs have been published in the past years based on the traveling-wave principle. In general, traveling wave motors require at least two piezoelectric elements shifted in space, which are excited by AC signals shifted in phase. As a result, two-directional rotation can be achieved by changing a phase angle. The traveling wave principle is interesting because of its functional characteristics (twodirectional operation), but complex when realizing the design [4], [5]. Another principle to drive micro-motors is a standing wave. Benefits of this method are a single-phase driving method, which allows unidirectional rotation, and a relatively simple mechanical construction, which provides good opportunities for miniaturization [6].

This paper presents the design, construction, and operational characteristics of the developed flextensional piezoelectric micro-motor. The 2-mm-square motor, which is based on a meso-scale prototype [7], uses a composite stator, consisting of a metallic flextensional mode convertor, or "cymbal," bonded to a 2-mm-square piezoelectric plate. The cymbal converts contour-mode vibrations of the plate into oscillations in the cymbal, perpendicular to the stator plane. These are further converted into unidirectional rotational movement in a rotor pressed against the cymbal by means of an elastic-fin friction drive to produce the required rotary actuation [8]. The driving mechanism is very simple, since only a single-phase sinusoidal voltage is needed, in contrast to traveling wave-type motors [9], which need two-phase control electronics and are more difficult to manufacture. The manufacture of the micromotor used a combination of novel microfabrication processes, including electrolytic etching and a microstamping technique, to manufacture a matrix of 2-mm cymbals from a metal sheet. The cymbal matrix was further bonded onto the lead-zirconate-titanate (PZT) with an epoxy resin. Indirect adhesive bonding is especially attractive in the man- 
ufacturing of piezoelectric devices. It is important to stay below the Curie point, which is, for example, $328^{\circ} \mathrm{C}$ for PZT 4 [10], in order to avoid the need to re-pole the bonded structure. The operational characteristics of the practical micro-motor were evaluated using high-speed imaging to measure the mechanical transient characteristics of the rotor. Based on the analysis of the images and a knowledge of the moments of inertia of the rotating parts (the rotor and encoder) and the acceleration, it was possible to calculate the torque. Measurement of the transient characteristics in this noncontact manner permitted the characterization of torques in the range of a few nNm's. Alternative contactbased methods, such as pulley-brake or using an external encoder, would have produced more frictional losses and would have made measurements difficult in this range [11]. Parallel measurements of the electrical characteristics such as supply voltage, current, and phase angle allowed measurement of the motor's efficiency.

\section{Design And Operational Principle}

The design of the micro-motor is shown in Fig. 1. A square plate stator is attached at the plate's center point to allow free contour movement of the PZT driver. A static load is applied to press the rotor in contact with the cymbal, and some lateral movement is allowed at the shaft to ensure even contact. The rotor has a jewel bearing in the middle to align the bias force pin. The jewel has a so-called olive-shape center to facilitate centering of the bias force pin. The practical dimensions of the motor are tabulated in Table I. An operation of the flextensional micro-motor is as follows (in outline): The metallic cymbal flextensional amplifier converts vibrations of the piezoelectric plate to oscillations of the metal cymbal in a direction principally perpendicular to its plane. An elastic-fin rotor [12] further converts these cymbal oscillations to rotary actuation via three inclined fins pressed out of the rotors. As the vibrating surface is moving upward (along the $z$-axis), the tip of each fin is held in contact with its surface by static friction. The rotation is generated by the horizontal component of the reactive force. When the vibrating surface is moving downward, the tips of the fins slip across the vibrating surface. Speed and torque are adjusted by varying the frequency and amplitude of the (single-phase) sinusoidal supply voltage.

\section{Microfabrichtion And Motor Construction}

A PZT wafer (Ferroperm PZ26 ${ }^{\mathrm{TM}}, \oslash 50 \mathrm{~mm}, t=2 \mathrm{~mm}$ ) was lapped to $235-\mu \mathrm{m}$ thickness. The flatness across the surface of the PZT was measured as $\pm 5 \mu \mathrm{m}$. Ti/Au electrodes were RF sputtered onto the lapped surface. The $\mathrm{Ti}$ and $\mathrm{Au}$ thicknesses were $\sim 8$ and $100 \mathrm{~nm}$, respectively. The surface roughness was measured as $R_{a}=0.2 \mu \mathrm{m}$ using a Dektak 3ST surface profiler (Veeco Instruments Ltd., Cambridge, UK).
TABLE I

Variables of the Practical Micro-Motor.

\begin{tabular}{ll}
\hline Rotor variables & Cu encoder $(\mathrm{mm})$ \\
\hline Rotor diameter, $d_{r}$ & 4.9 \\
Rotor thickness, $t_{r}$ & 0.038 \\
Fin length, $l_{f}(1 ; 2 ; 3)$ & $0.17 ; 0.16 ; 0.15$ \\
Fin width, $w_{f}(1 ; 2 ; 3)$ & $0.08,0.08,0.11$ \\
Fin angle, $\theta(1 ; 2 ; 3)$ & $15 ; 24 ; 30$ \\
Radius of contact, $r_{r}{ }^{*}(1 ; 2 ; 3)$ & $0.43 ; 0.36 ; 0.47$ \\
\hline Jewel dimensions & $(\mathrm{mm})$ \\
\hline Jewel diameter, $d_{j}$ & 0.7 \\
Jewel hole diameter, $d_{j h}$ & 0.08 \\
Jewel height, $h_{j}$ & 0.2 \\
\hline Stator dimensions & $(\mathrm{mm})$ \\
\hline PZT width, $w_{s}$ & 2.03 \\
PZT length, $l_{s}$ & 1.96 \\
PZT thickness, $t_{p}$ & 0.235 \\
Top electrode thickness, $t_{t}$ & 0.0001 \\
Bottom electrode thickness, $t_{b}$ & 0.01 \\
Bond thickness $t_{b o}$ & 0.004 \\
Radius of mechanical boundary, $r_{p}$ & 0.40 \\
Cymbal radius, $r_{c}$ & 0.95 \\
Bonding ring radius, $r_{c b}$ & 0.88 \\
Cymbal apex radius, $r_{c a}$ & 0.64 \\
Cymbal's center hole radius, $r_{c c}$ & 0.21 \\
Cymbal height, $h_{c}$ & 0.165 \\
Cymbal side angle, $\alpha$ & $35^{\circ}$ \\
Cymbal thickness, $t_{c}$ & 0.048 \\
\hline${ }_{r} r$ is defined $i n$ the midne of the $F i n$.
\end{tabular}

${ }^{*} r_{r}$ is defined in the middle of the Fin.

Manufacturing of the cymbals was based on the use of electrochemical micromachining. A stainless steel metal sheet (AISI $316 \mathrm{HV}$ 210) was cleaned of organic compounds with Micro-90 ${ }^{\circledR}$ (International Products Corporation, London, UK) cleaning solvent. Both sides of the wet sample were laminated with a photoresist $30 \mu \mathrm{m}$ in thickness using a Dynachem $350 \mathrm{HR}$ hot roll laminator. The photoresist was exposed with UV-light (Riston PC Printer 130) through a plastic phototool having cymbal features in it. The cymbal matrix was electrolytically etched using ferric chloride $\left(\mathrm{FeCl}_{3}\right)$. It was important that only the features to be etched were in contact with electrolyte during etching. The backside of the sample electrode was covered with an electric insulating tape. Only the top was left uncovered for the electrical connections. Both of the electrodes were assembled in parallel ( pacing $=10 \mathrm{~mm}$ ) in a specially engineered plastic jig. The sample electrode was connected to the anode $(+)$ and the back electrode to the cathode $(-)$. In practice, the etching time for a stainless steel cymbal matrix (AISI $316 \mathrm{HV} 210, t=40 \mu \mathrm{m}$ ) was 22 min when the area etched was $\sim 426 \mathrm{~mm}^{2}$. The starting direct current and voltage were adjusted to $1200 \mathrm{~mA}$ and $2.12 \mathrm{~V}$, respectively. One sample of the etched cymbal matrix is shown in Fig. 2.

The cymbal discs in a sheet were individually deformed to the designed cavity by stamping with matching punches and dies (Fig. 3). Figs. 4 and 5 show these in close up. Four guiding pins, shown in Fig. 4, center the tool parts. As a result, a 3-D matrix with 52 cymbals was achieved. 


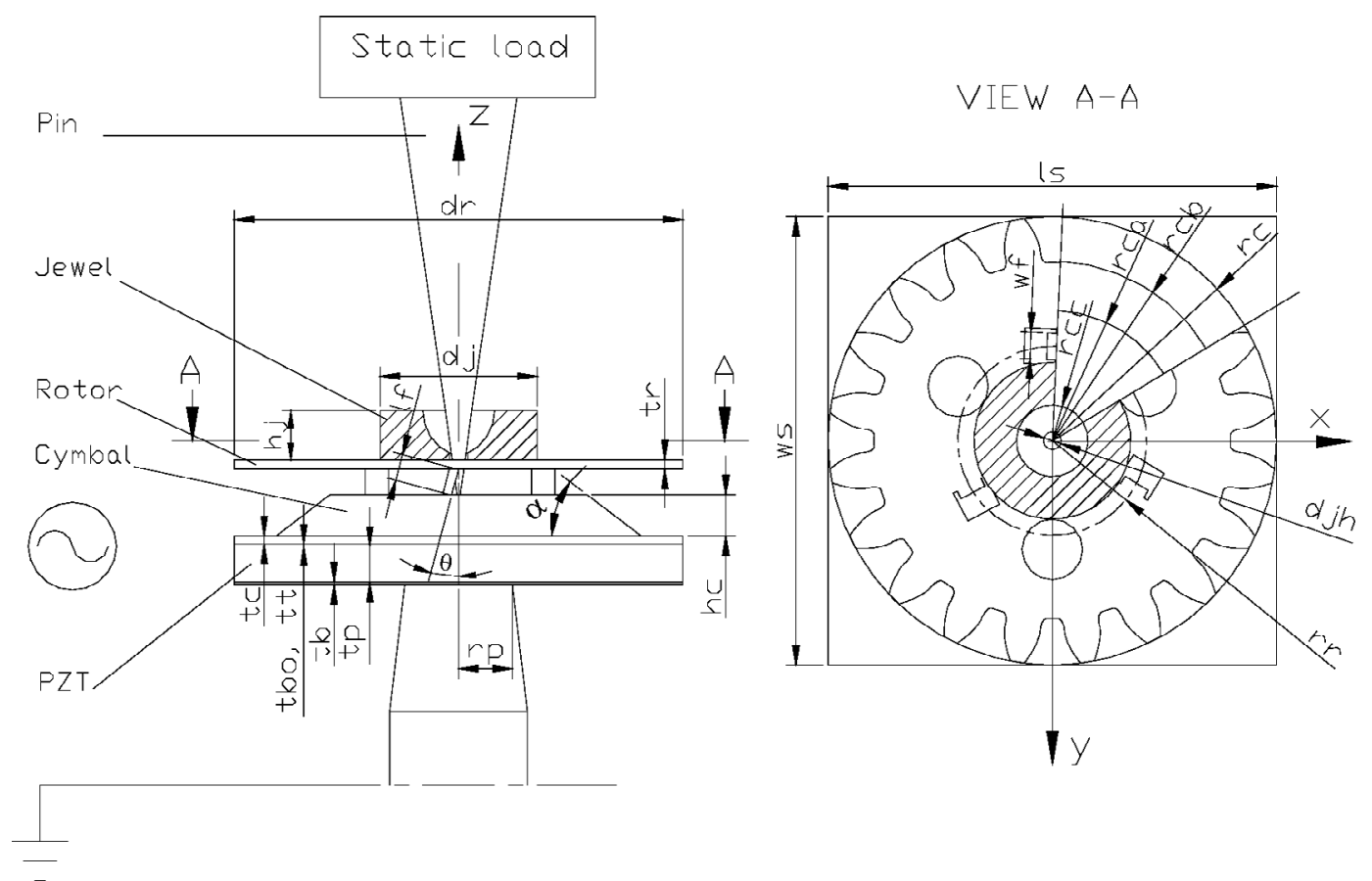

Fig. 1. Schematic diagram of the micro-motor construction.
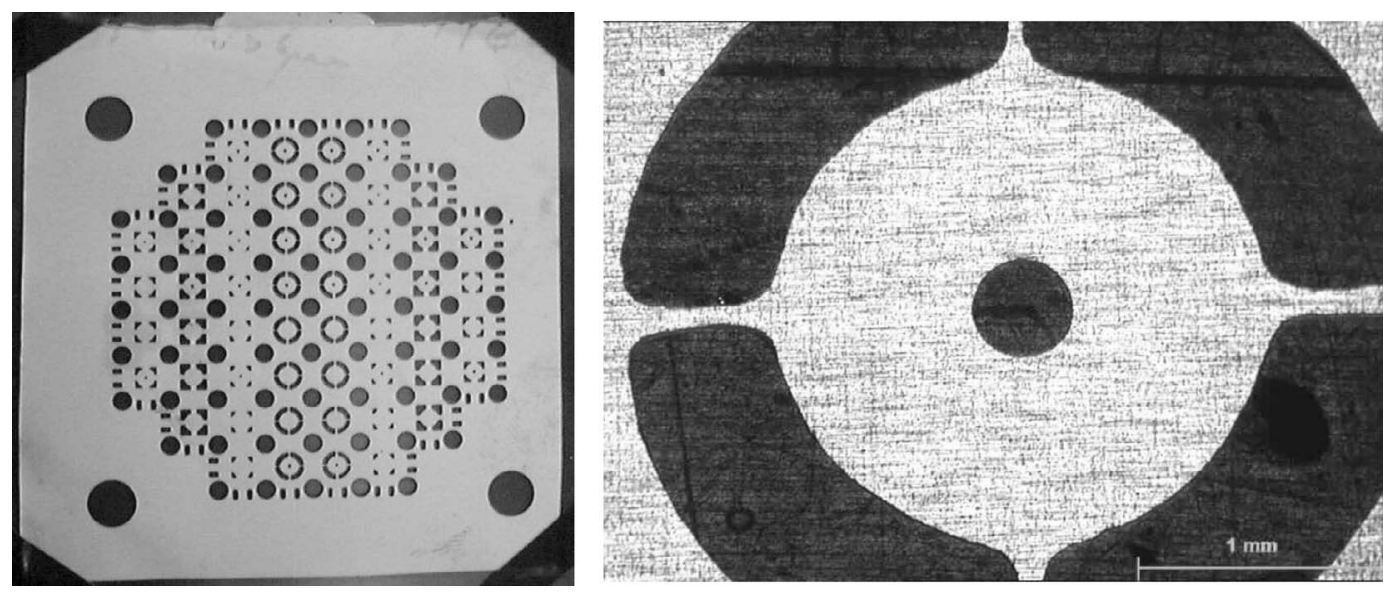

Fig. 2. At left, a matrix of cymbal discs. At the right is shown the close-up of the individual disc etched from a stainless steel. Four supports locate a disc.

The 3-D cymbal matrix was bonded onto the PZT disc using indirect adhesive bonding with an epoxy resin. The surface of the PZT and the cymbal matrix were both cleaned with $4 \%$ Micro- $90{ }^{\circledR}$, the cymbals ultrasonically for $10 \mathrm{~min}$ and the PZT by wiping. After this, the PZT was covered with the adhesion promoter Ken-React LICA 38 (mixture: $0.2 \%$ with isopropanol) from Kenrich Petrochemicals Inc. (Bayonne, NJ) and then rinsed in a spin-coating machine with isopropanol. Electrically nonconductive epoxy resin Epo-tek 301-2 was spin coated onto the PZT wafer. The bonding tool was coated with Loctite Frekote ${ }^{\circledR}$ Aqualine ${ }^{\mathrm{TM}}$ C-200 mould release agent (Henkel Loctite Ltd., Hartfordshire, UK) in order to avoid sticking. Bias force of $75 \mathrm{~N}$ at temperature of $82^{\circ} \mathrm{C}$ was applied for three hours. After bonding, the electrical connections were opened by oxygen plasma etching (ashing) in a Polaron PT 7160 RF Plasma Barrel Etcher (Polaron PLC, Whatford, Hertz, UK). The stators were separated from each other with a semiconductor saw (MicroAce Series 3 from Loadpoint Ltd., Swindon, Wiltshire, UK). A cymbal matrix bonded onto the PZT can be seen in Fig. 6 .

A scanning electron microscope (SEM) image of a completed stator, after applying the signal wire, is shown in Fig. 7. A low-frequency resistance of the electrical connections $(50 \mathrm{kHz})$ was measured using a Wayne Kerr Precision Component Analyzer 6425 (Wayne Kerr Electronics, Chichester, West Sussex, UK) integrated with a precision probe station. Resistance on the top was measured as $2 \Omega$ across the corners of a square plate. The bottom electrode (fired-on $\mathrm{Ag}$ ) was checked between two points and gave a 

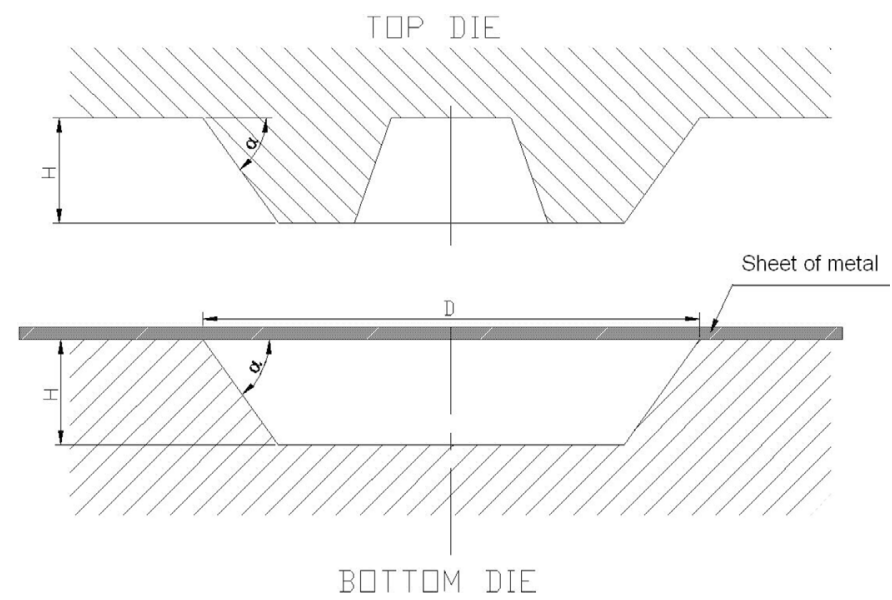

Fig. 3. Basic principle of the stamping technique. Parameters for D, $\mathrm{H}$, and $\alpha$ are $1.73 \mathrm{~mm}, 0.18 \mathrm{~mm}$, and $37^{\circ}$, respectively.

resistance of $100 \mathrm{~m} \Omega$. The resistance between the cymbal and the top electrode was measured as $8 \Omega$. Signal wire (Au, $t=40 \mu \mathrm{m}$ ) was bonded manually under a microscope by using CircuitWorks ${ }^{\circledR}$ CW2400 conductive silver loaded epoxy from Chemtronics (ITW Chemtronics, Kennesaw, GA). The bottom of the stator (center point) was connected to the steel post by the same conductive epoxy. Prior to testing, the post was connected into the electrical ground.

Rotors (Fig. 8 and Fig. 9) were manufactured using the same electrolytic etching process as explained above. In practice, the etching time for the stainless steel (AISI 302 (FE/CR18/NI8) HARD), $t=25 \mu \mathrm{m}$ ) rotor matrix was $10 \mathrm{~min}$ when the area etched was $\sim 126 \mathrm{~mm}^{2}$. The starting direct current and voltage were $1210 \mathrm{~mA}$ and $2.89 \mathrm{~V}$, respectively. Etching time for the encoder matrix (annealed copper, $t=38 \mu \mathrm{m}$ ) was $22 \mathrm{~min}$ when the area etched was $\sim 26 \mathrm{~mm}^{2}$. The starting direct current and voltage were $1235 \mathrm{~mA}$ and $4.43 \mathrm{~V}$, respectively. The fins were manually bent to the desired angle under the microscope. The bearing (watch jewel) was also manually bonded under the microscope.

\section{Stator Characterization}

Impedance characteristics of the micro-stator were evaluated by an impedance analyzer HP4192A. In practice, the stator was fixed onto the steel post. No rotor was attached during the measurements. An excitation voltage of $1 \mathrm{~V}_{\mathrm{rms}}$ was connected to the signal wire on the top electrode, and the bottom electrode was grounded via a steel post. Impedance and phase characteristics were downloaded to the database for analysis. The close-ups of the characteristic are shown in Fig. 10. Resonance $\left(f_{m}, Z_{m}\right)$ and antiresonance $\left(f_{n}, Z_{n}\right)$ frequencies and impedances are $222 \mathrm{kHz}$, 4401 ohms, $223.5 \mathrm{kHz}$, and 4942 ohms, respectively. The mechanical quality factor $Q_{m}=53$ was calculated by using (1). Capacitance $C_{d}=\varepsilon_{r} \varepsilon_{0} A / t_{s}=0.2 \mathrm{nF}$, where $\varepsilon_{r}=1300$ (relative permittivity of PZ26 at $1 \mathrm{kHz}$ ), $\varepsilon_{0}=$
$8.854^{*} 10^{-12} \mathrm{Fm}^{-1}$ (vacuum permittivity), $A=4 \mathrm{~mm}^{2}$, and $t_{s}=0.235 \mathrm{~mm}$ (thickness of the practical PZT element). The effective coupling coefficient $k_{\text {eff }}$ was evaluated from (2) as 0.12 .

$$
\begin{aligned}
Q_{m} & =\frac{f_{n}^{2}}{2 \pi f_{m} Z_{m} C_{d}\left(f_{n}^{2}-f_{m}^{2}\right)} . \\
k_{\mathrm{eff}}^{2} & \approx \frac{C_{m}}{C_{d}+C_{m}}=\frac{f_{n}^{2}-f_{m}^{2}}{f_{n}^{2}} .
\end{aligned}
$$

\section{Motor Characterization}

In practice, the rotor was assembled on the top of the cymbal under a microscope by a pair of needles. After this, bias force, i.e., a static load (pin + load) was applied into the middle of the jewel bearing by a specially engineered sharp pin $0.8 \mathrm{~mm}$ in diameter. The encoder disc used in the characterization of the motor is pictured in Fig. 11. The $\mathrm{Cu}$ disc is $5 \mathrm{~mm}$ in diameter and $36 \mu \mathrm{m}$ in thickness and has 70 holes on its outer radius. The black line in the northwest of the disc is used as an indicator in transient and constant speed measurements as will be discussed below. Small holes on the disc's outer radius are used for fiberoptic sensor-based constant-speed measurements.

\section{A. Motor's Constant Speed}

An integrated encoder technique was used in parallel with the stroboscopic measurements when the constant speed of the motor was evaluated. In this technique, the through-beam sensor head (FU 32) was connected to fiber optic amplifier unit (FS-V11P), which converted the optical signal to the digital pulses [13]. In stroboscopic measurements, the flash rate of the stroboscope was adjusted to a level where the black marking line became visible when the motor was operated. The constant speed was then read from the digital oscilloscope (National Instruments PCI-5102 [14]) based on the pulse rate. The rotational speeds obtained with a stroboscope and fiberoptic probe were $11.2 \mathrm{~s}^{-1}$ and $10.2 \mathrm{~s}^{-1}$, respectively. The latter is approximately $9 \%$ lower than that obtained with the stroboscope. The difference may have been caused by the uneven holes in the encoder disc (Fig. 11) or visual error in the stroboscopic method.

\section{B. Evaluation of the Motor's Transient Characteristics}

Perhaps the most important measurements to characterize the micro-motor's mechanical characteristics are those of acceleration and deceleration. Once acceleration is known, the mechanical torque of the motor can be calculated from the rotor moment of inertia [15] (see (8)). Several potential measurement methods can be found in the macro-scale. One of the most common methods is to use a ready-made encoder. The rough estimation from the similar macro-motor shows that the use of the integrated encoder technique is difficult to apply since the number of 

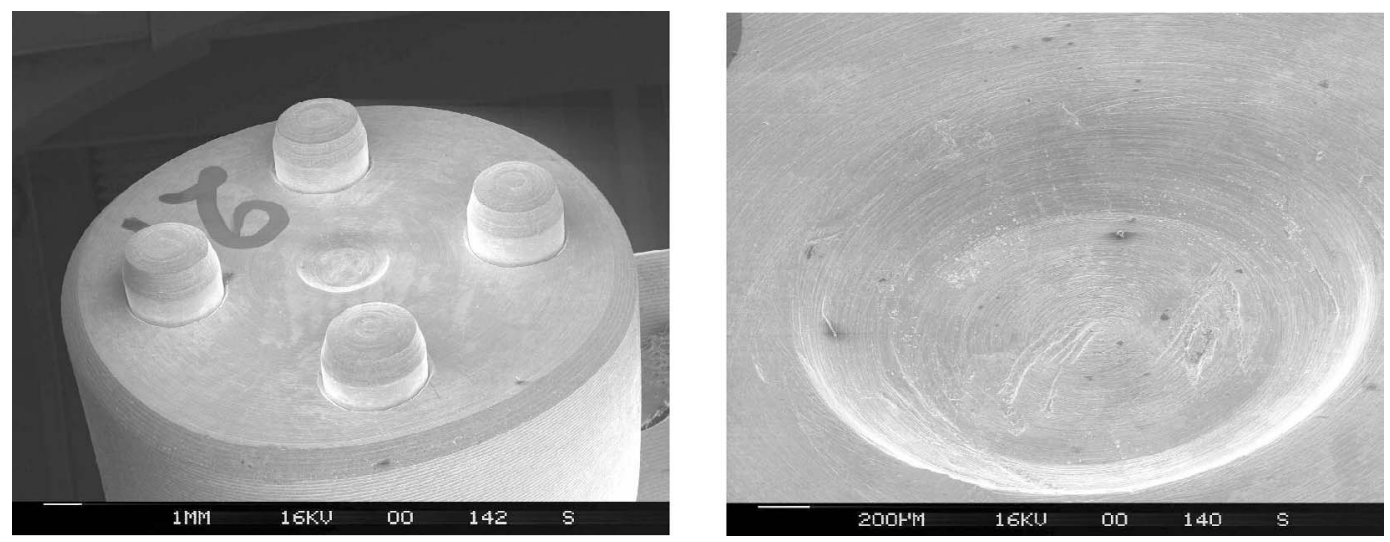

Fig. 4. On the left, view of the base part with four guiding pins; on the right, a close-up of the die in the base part.

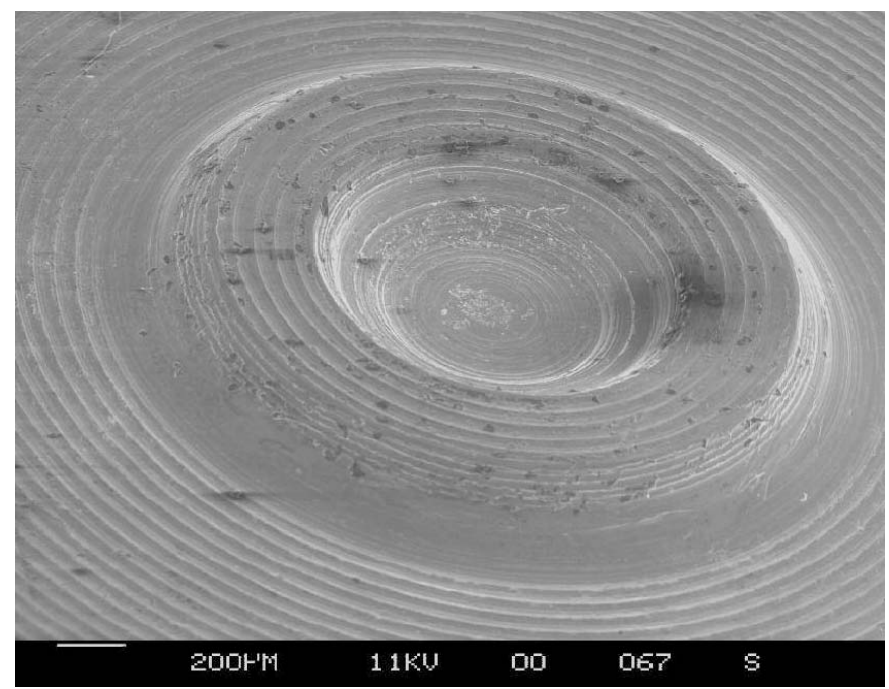

Fig. 5. A close-up of the matching die in the top part.

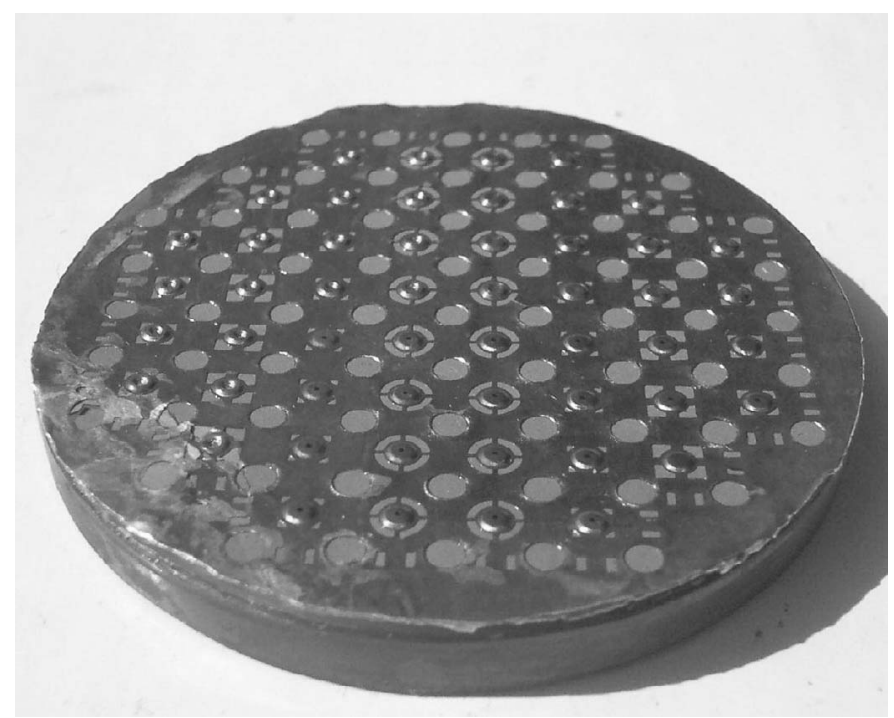

Fig. 6. A matrix of cymbals bonded onto the PZT.

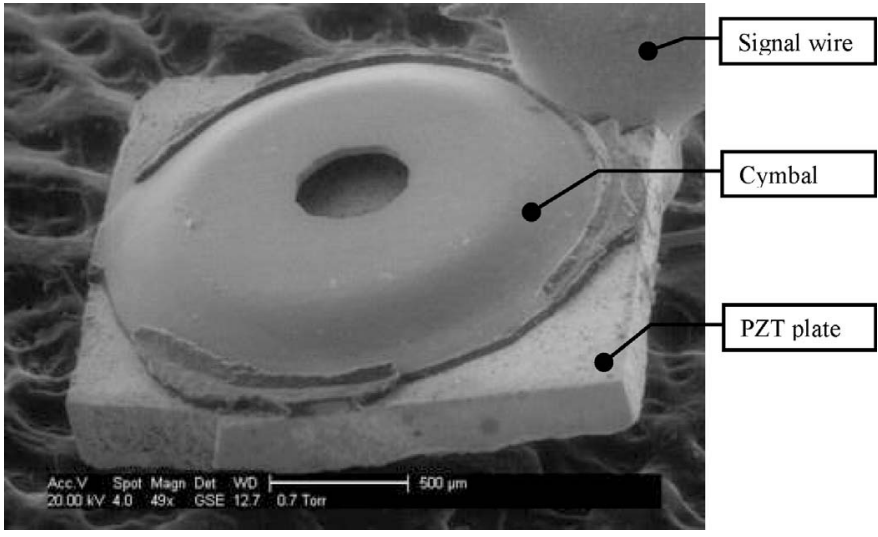

Fig. 7. SEM image of the practical stator with electric wire bonded onto the top right-hand corner.
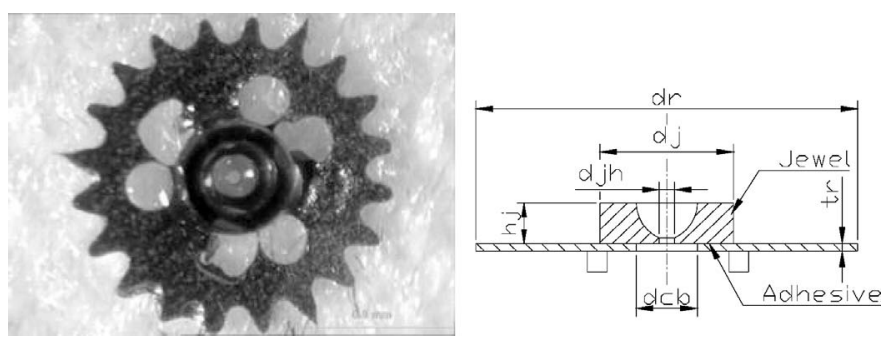

Fig. 8. On the left, an image of the ready stainless steel rotor with a jewel bearing; on the right, a cross-sectional view of the jewel and the rotor.

encoder features is inadequate. In comparison, the similar macro-motor with a stator of size $25 \mathrm{~mm}$ (side length of the square plate is $25 \mathrm{~mm}$ ) has stall torque of $0.47 \mathrm{Nmm}$ [16]. The dimensional scale for the frictional force is two $\left(L^{2}\right)$ and for the length one $\left(L^{1}\right)$ [17]. The dimensional scale for the torque is then three, because the torque is a product of frictional force and fin-stator contact radius $\left(L^{2} \times L^{1}=L^{3}\right)$. As a comparison dimension between macro- and micro-scale, the side lengths of the stators can be used, which are 25 and $2 \mathrm{~mm}$, respectively. This leads to the scale ratio of $L=25 / 2=12.5$. The estimated micro-motor torque is then $0.47 \mathrm{Nmm} / 12.5^{3} \approx 0.24 \mu \mathrm{Nm}$. 


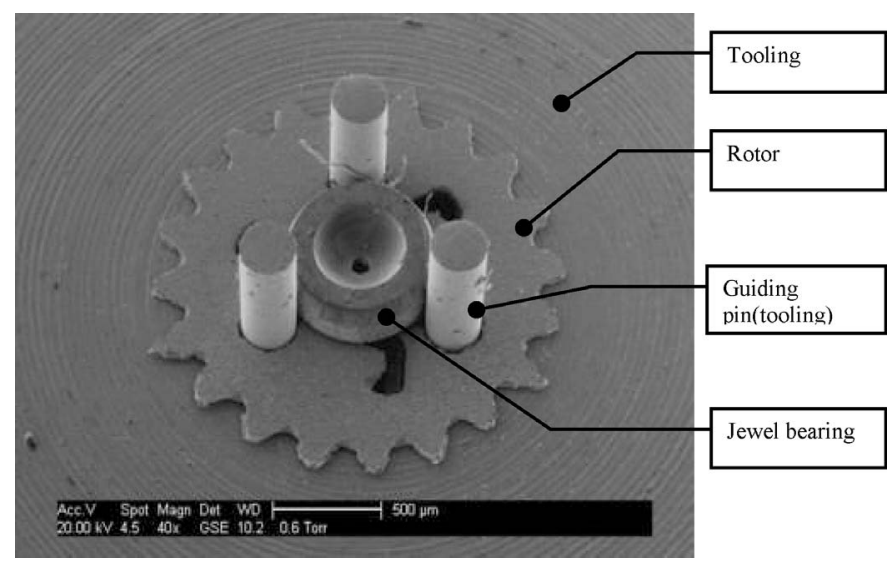

Fig. 9. SEM image of the fin bending and bearing centering tooling. The rotor is mounted onto the three centering pins and the jewel bearing is located at the middle. The diameter of each pin is $0.25 \mathrm{~mm}$.

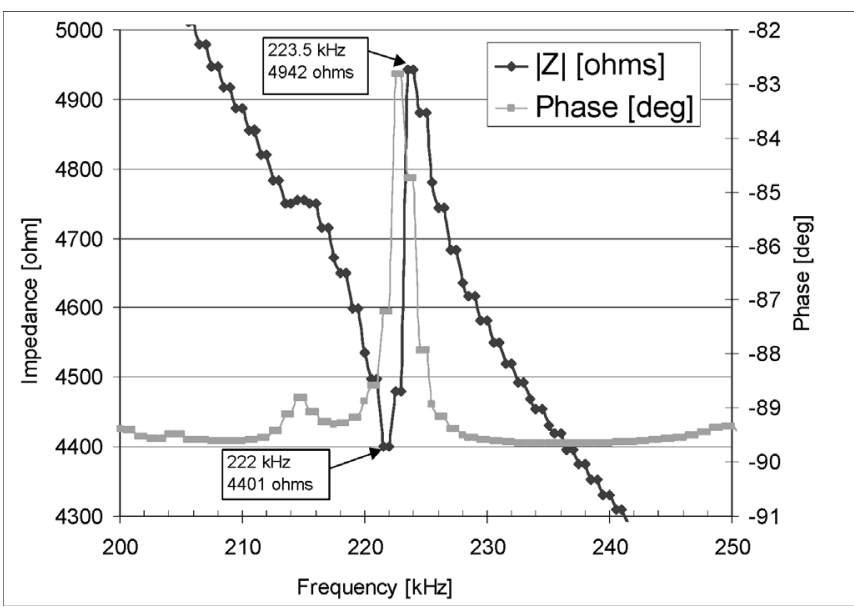

Fig. 10. Measured impedance and phase characteristics of the practical micro-stator close to operational frequency.

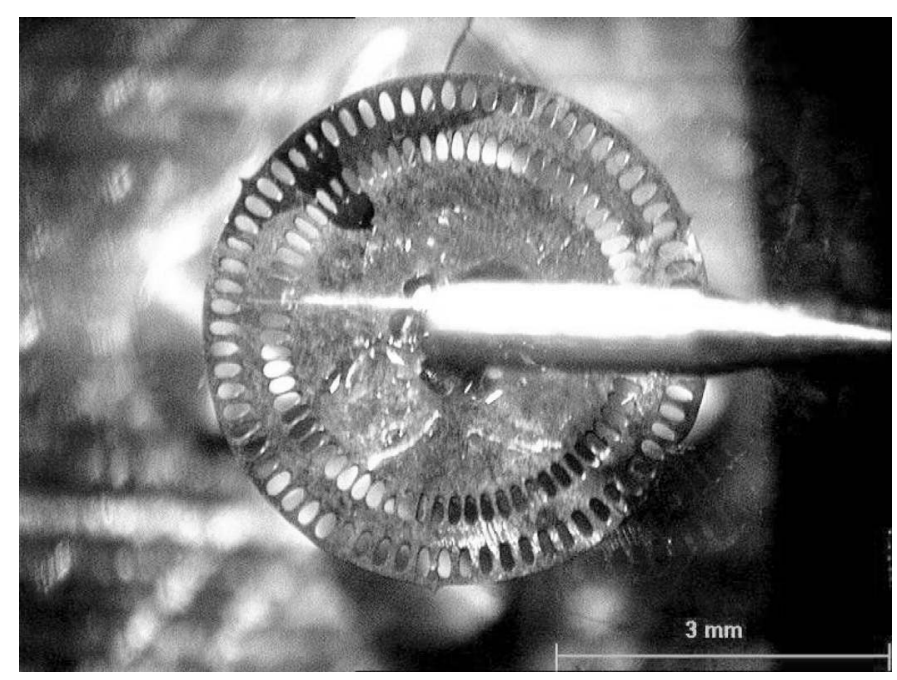

Fig. 11. Top view of the micro-motor with the $\mathrm{Cu}$ encoder disc $(\oslash 5 \mathrm{~mm})$.
The acceleration for the micro-motor is now evaluated as $15,484 \mathrm{rad} / \mathrm{s}^{2}$ and the time for acceleration $t_{a}=4.5 \mathrm{~ms}$, where the maximum speed is $11.2 \mathrm{~s}^{-1}(70.4 \mathrm{rad} / \mathrm{s})$ and the moment of inertia of $\mathrm{Cu}$ encoder $\mathrm{Jzz}=15.5 \times 10^{-12} \mathrm{kgm}^{2}$. The time for one revolution is $1 / 11.2 \mathrm{~s} \approx 89 \mathrm{~ms}$. Using a linear relationship between the $t_{a}$, time per one revolution, and a number of encoder features per one revolution, the number of encoder features per $t_{a}$ becomes approximately three. This shows that the number of encoder features in a region of interest is not sufficient to evaluate acceleration. The minimum number of spatial sample points is four, in order to evaluate linear approximation of acceleration, which is the second derivative of displacement $\left(d^{2} s / d t^{2}\right)$. Another way to use the encoder principle would be to increase the moment of inertia of the encoder in order to increase $t_{a}$, as was, for example, done in [18]. Because of difficulties in using the integrated encoder technique in the transient measurements, here an alternative way to measure micro motor's transient characteristics using a highspeed camera will be described.

\section{High-Speed Imaging}

The Phantom V4.0 is a color high-speed digital imaging system. The camera uses a CRS-CMOS imaging sensor with $512 \times 512$ pixel resolution. The frame rate can be adjusted from 1000 pps (i.e., pictures per second) with full pixel resolution up to the $30,000 \mathrm{pps}$ with allocated memory use. The imager is controlled via a FireWire ${ }^{\mathrm{TM}}$ (IEEE 1394) using Phantom ${ }^{\circledR}$ image analyzing software. Images are grabbed to the $256-\mathrm{Mb}$ internal memory. A total of 1024 images can be stored in one second of time with 1000 pps. Once images are captured from the camera, they can be played on the screen and processed [19].

In order to gather angular velocity data, the position of the black marking line on the encoder disc (see Fig. 11) was recorded using the ready-built algorithm in Phantom ${ }^{\circledR}$ software. Collected points were arranged in a Cartesian co-ordinate system as a function of image numbers $(N)$ and time $\left(t_{N}\right)$. The linear approximation of the radial displacement $z_{N}=\sqrt{\left(X_{r, N}-X_{r, N-1}\right)^{2}+\left(Y_{r, N}-Y_{r, N-1}\right)^{2}}$ can be defined from co-ordinate points $X_{N}$ and $Y_{N}$. Since the frame dependent time $t_{N}$ is known from the sampling rate, the velocity $v_{N}$ can be calculated as shown in (3):

$$
v_{N}=\frac{z_{N}}{t_{N}-t_{N-1}} .
$$

Collected points $\left(X_{N}, Y_{N}\right)$ were further converted to an angular velocity using (4), where the radius $r_{N}$ was defined as $r_{N}=\sqrt{X_{N}^{2}+Y_{N}^{2}}$ :

$$
\omega_{N}=\frac{v_{N}}{r_{N}} .
$$

It is now possible to evaluate the angular acceleration by taking the derivative of the angular speed (5):

$$
\alpha_{N}=\frac{\omega_{N}-\omega_{N-1}}{t_{N}-t_{N-1}} .
$$




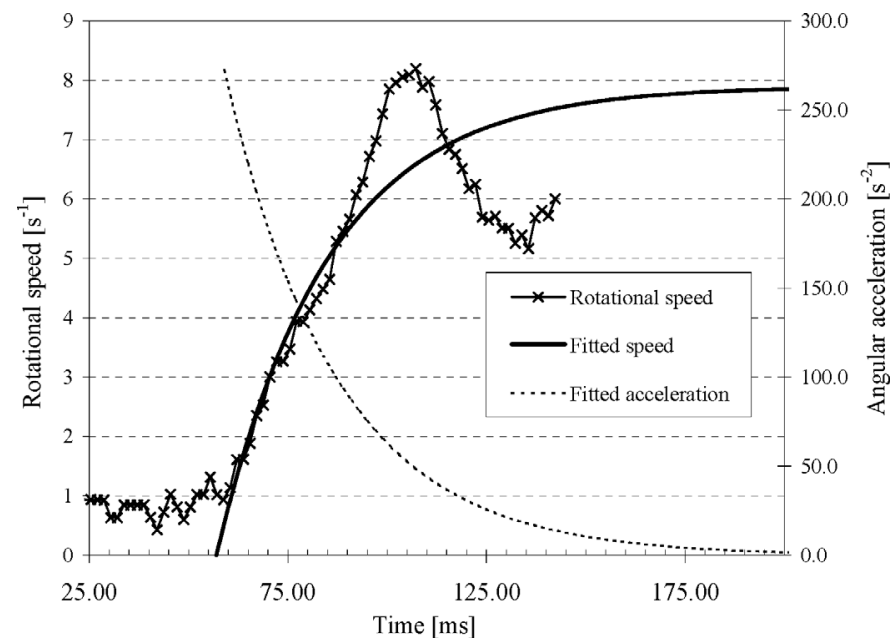

Fig. 12. Micro-motor's transient characteristics represented as a function of time.

Now the angular displacement $\theta_{N}$ can be developed from linear displacement $z_{N}$ by using a cosine rule (6):

$$
\theta_{N}=\alpha \cos \left(-\frac{\left(z_{N}^{2}-2 r^{2}\right)}{2 r^{2}}\right) .
$$

As a result, the rotational speed can be represented as a function of time (Fig. 12). The shown transient characteristics were achieved by averaging eight measurement points in series. The fitted speed is based on (10), where the time constant $\tau_{a}=28 \mathrm{~ms}$. The fitted angular acceleration is achieved as a derivative of the fitted rotational speed (5).

The maximum acceleration $\alpha_{\max }=270 \mathrm{~s}^{-2} \approx$ $1700 \mathrm{rad} / \mathrm{s}^{2}$ can now be evaluated from Fig. 12. The angular displacement $\theta$ during the acceleration is approximately $43^{\circ}$. It is important to notice that the step response of the motor is underdamped. Thus a first-order approximation does not fully model the motor's transient characteristics. Underdamping may be an indication of insufficient frictional contact between the rotor and the stator. Another indication of the insufficient friction is the stepwise movement of the rotor. When the data were visually analyzed, the motion indicated stick/release while accelerating and during the constant speed. In practice, the fin dimensions are not equal in the practical micro-motor (see Table I), which can easily be an origin of the stepwise movement and underdamped characteristics. It should be noted that noise in the video signal, manually digitized coordinate points, and lack of pixel resolution generated uncertainty in the measurements.

The achieved deceleration characteristics of the micromotor are represented in Fig. 13. The deceleration $\alpha_{d}=$ $-730 \mathrm{~s}^{-2} \approx-4600 \mathrm{rad} / \mathrm{s}^{2}$ is evaluated by $d \omega / d t[(5)$, $\left.t_{1}=114 \mathrm{~ms}, t_{0}=102 \mathrm{~ms}, \omega_{1}=1.6 \mathrm{~s}^{-1}, \omega_{0}=10.4 \mathrm{~s}^{-1}\right]$. The fall time is $t_{d}=\tau_{f}=12 \mathrm{~ms}$. Angular displacement during the deceleration is approximately $20^{\circ}$. It is interesting to notice that the speed is not constant prior to deceleration. The same variation in speed can also be seen

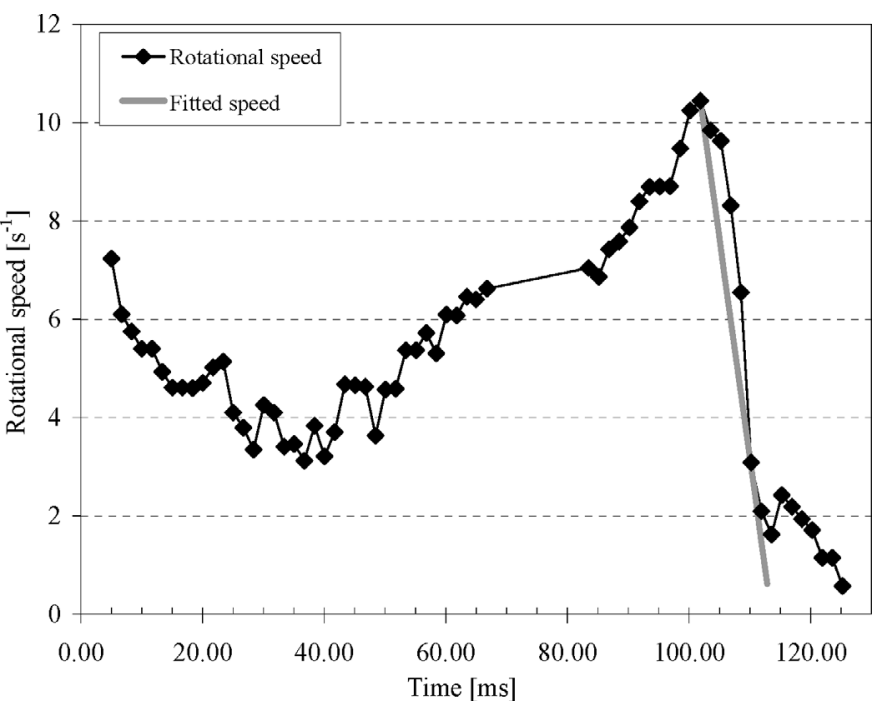

Fig. 13. Micro-motor's deceleration characteristics.

after the acceleration. The variation of the data points is an indication of the stick/release of the rotor prior to deceleration.

\section{Electrical Characteristics and Efficiency}

Parallel to acceleration and deceleration measurements, the electrical characteristics of the micro-motor were evaluated by the PC-integrated dual-channel digital oscilloscope (National Instruments PCI-5102 [14]). Both of the channels were logged simultaneously, which allowed phase measurements.

The electrical power input, mechanical power output, and efficiency are defined with (7). $P_{\text {loss }}$ defines the electrical power loss generated by the measurement electronics, $T_{m}$ is the torque of the motor $(\mathrm{Nm})$, and $\omega$ is the angular velocity $(\mathrm{rad} / \mathrm{s}) . U_{\text {in }}$ and $I_{\text {in }}$ are RMS voltage and current, respectively, supplied to motor. $\operatorname{Cos} \phi$ is a power factor, where $\phi$ is the phase difference between the voltage and current signals.

$$
\eta=\frac{P_{\text {out }}}{P_{\text {in }}-P_{\text {loss }}}=\frac{T_{m} \omega}{U_{\text {in }} I_{\text {in }} \cos \phi-P_{\text {loss }}} 100 \% .
$$

\section{E. Torque and Frictional Coefficient from the Transient Characteristics}

The torque of the piezoelectric motor can be defined using (8):

$$
T_{m}=J_{z z} \alpha=J_{z z} \frac{d \omega}{d t}=J_{z z} \frac{d^{2} \theta}{d t^{2}} .
$$

Once the speed decreases from the no-load speed $\left(\omega_{\max }\right)$ to zero, the torque increases toward the stall torque $\left(T_{m, \max }\right)(9)$ :

$$
\omega=\omega_{\max }\left(1-T_{m} / T_{m, \max }\right) .
$$


The solution for the rise curve can be represented with (10) after $T_{m}$ has been eliminated from (8) and (9). The term $\tau_{r}$ represents the time constant and is given in (11).

$$
\begin{aligned}
\omega & =\omega_{\max }\left[1-\exp \left(-t / \tau_{r}\right)\right] . \\
\tau_{r} & =J_{z z} \omega_{\max } / T_{m, \max } .
\end{aligned}
$$

The maximum torque $T_{m, \max }$ can be defined from the time constant $\tau_{r}$ when the moment of inertia is known. In order to define the speed/torque characteristics, the angular speed derivative $d \omega / d t$ must be calculated at every measurement point on the rise curve and substituted into (8).

After the vibrator is turned off, the frictional torque $\left(T_{f}=\mu m g r_{r}\right)$ decelerates the rotation linearly (12). The $\mu, m, g$, and $r_{r}$ are the frictional coefficient, mass of the rotor $\left(m_{r}\right)$ and load $\left(m_{\text {load }}=145 \mathrm{mg}\right)$, gravity $\left(9.81 \mathrm{~ms}^{-2}\right)$, and the radius of the contact between rotor and stator, respectively.

$$
\omega=\omega_{\max }\left(1-t / \tau_{f}\right)
$$

The time constant for fall time $\tau_{f}$ is written in a following form:

$$
\tau_{f}=J_{z z} \omega_{\max } / T_{f}
$$

By measuring the $\tau_{f}$, the frictional coefficient $\mu$ can be estimated by (14):

$$
\mu=\frac{J_{z z} \omega_{\max }}{m g r_{r} \tau_{f}}
$$

\section{F. Operational Characteristics}

The operational characteristics are based on the transient characteristics of the micro-motor. The achieved electrical and mechanical characteristics are tabulated in Table II. Acceleration characteristics consist of frequency $(f)$, acceleration time constant $\left(\tau_{a}\right)$, angular displacement during acceleration $\left(\theta_{a}\right)$, achieved maximum rotational speed $\left(N_{a, \max }\right)$, and maximum angular speed $\left(\omega_{a, \max }\right)$. Deceleration characteristics consist of the same parameters as are shown for the acceleration. Also, due to the linear nature of the deceleration, the deceleration $\left(\alpha_{d}\right)$, frictional torque $\left(T_{f}=T_{m, d}\right)$, and generated power $\left(P_{\mathrm{out}, d}\right)$ are included. In addition, calculated dynamic frictional coefficients $(\mu)$ are shown in the end. Electrical characteristics were recorded at the steady state conditions and are the same for the acceleration and the deceleration analyses. The first three variables starting from the left are: the measured voltage $\left(U_{\text {in }}\right)$, current $\left(I_{\text {in }}\right)$, and phase angle $(\phi)$. Then there are shown the input power $\left(P_{\text {in }}\right)$ and the resistive power loss $\left(P_{\text {loss }}\right)$. This approach differs from [15], where the electrical characteristics were logged simultaneously with the acceleration measurements. However, based on the electrical measurements with a similar macro-motor, the power input values measured in steady state conditions with different torques were in $1 \%$ of margin with no practical effect

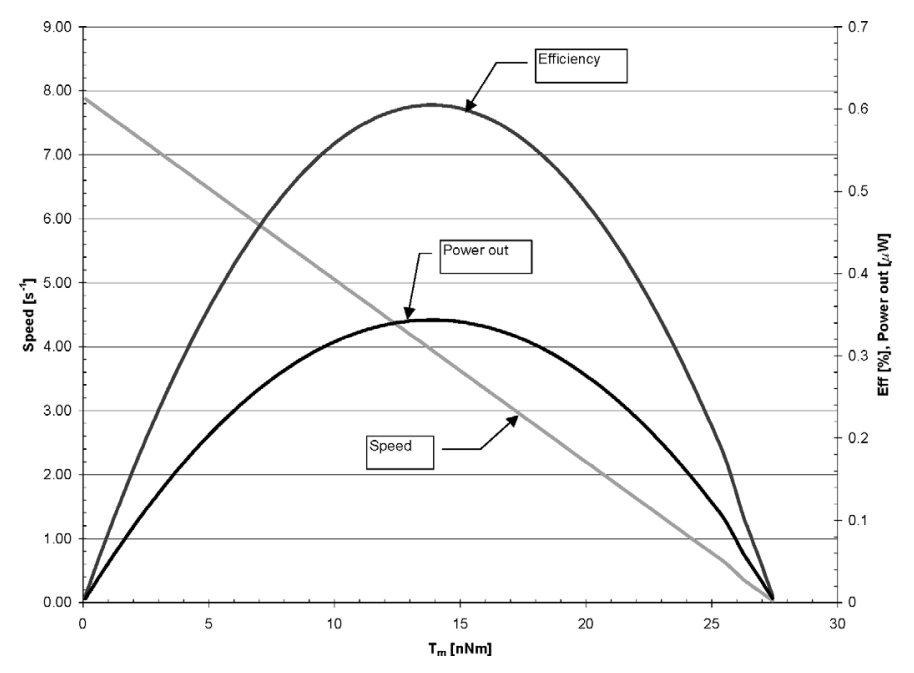

Fig. 14. Fitted speed torque characteristics of the flextensional piezoelectric micro-motor.

on the efficiency [11]. The calculated frictional coefficient is in accordance with findings of previous research (for $\mathrm{BeCu}$, $\mu=0.17[4])$.

Fig. 14 represents the fitted speed torque characteristics of the micro-motor with the following sampling conditions: $\Delta t=0.1 \mathrm{~ms}$ when $t \leq 1.3 \mathrm{~ms}$, and $\Delta t=0.5 \mathrm{~ms}$ when $t>1.3 \mathrm{~ms}$. The achieved maximum torque comes as $T_{m, \max }=0.027 \mu \mathrm{Nm}$. It is interesting to note that the achieved maximum torque is $\sim 10 \%$ of the estimated value based on the pulley-brake torque measurements of a similar macro-motor $\left(T_{m \text {,estimate }}=0.24 \mu \mathrm{Nm}[11]\right)$. The difference could be explained by the bearing configuration. The macro-motor used a ball bearing and the micro-motor a jewel sliding bearing (i.e., a coefficient of friction for rolling is generally smaller than it is for sliding). Detailed analysis related to the frictional losses is not included in this study. The achieved maximum efficiency was evaluated as $\sim 0.6 \%$ (Fig. 14).

\section{Discussion}

This paper has presented the experimental design, construction, and operational characteristics of a new type of piezoelectric ultrasonic micro-motor in a range of $2 \mathrm{~mm}$. The design used the same principle as a similar macromotor reported previously [7]. The design was scaled down by a factor of 12.5 and a different bearing configuration was adapted. The macro-motor used a ball bearing and here a jewel bearing was used. The motor design described here was especially designed to suit non-silicon MEMS manufacturing processes. Especially, the square plate stator gives advantages in matrix-based MEMS processes, since dicing-out of the devices can be made by using a standard semiconductor saw. The practical fabrication process included an electrolytic etching, which was used to fabricate rotors and stators from the metal sheet, and 3-D structures were achieved by a stamping technique. Stator structures were achieved after bonding the cymbal matrices onto the 
TABLE II

Achieved Electrical and Mechanical Characteristics of the Cu Encoder.

\begin{tabular}{|c|c|c|c|c|c|c|c|c|}
\hline \multicolumn{9}{|c|}{ Acceleration characteristics } \\
\hline $\begin{array}{l}f \\
(\mathrm{kHz})\end{array}$ & $\begin{array}{l}\tau_{r} \\
(\mathrm{~ms})\end{array}$ & $\begin{array}{l}\theta_{a} \\
(\mathrm{deg})\end{array}$ & $\begin{array}{l}N_{a, \max } \\
(1 / \mathrm{s})\end{array}$ & $\begin{array}{l}\omega_{a, \max } \\
(\mathrm{rad} / \mathrm{s})\end{array}$ & & & & \\
\hline 224 & 2850.00 & 43 & 8 & 50 & & & & \\
\hline \multicolumn{9}{|c|}{ Deceleration characteristics } \\
\hline $\begin{array}{l}f \\
(\mathrm{kHz})\end{array}$ & $\begin{array}{l}\tau_{f} \\
(\mathrm{~ms})\end{array}$ & $\begin{array}{l}\theta_{a} \\
(\mathrm{deg})\end{array}$ & $\begin{array}{l}N_{d, \max } \\
(1 / \mathrm{s})\end{array}$ & $\begin{array}{l}\omega_{d, \max } \\
(\mathrm{rad} / \mathrm{s})\end{array}$ & $\begin{array}{l}\alpha_{d} \\
\left(\operatorname{rad} / \mathrm{s}^{2}\right)\end{array}$ & $\begin{array}{l}T_{m, d} \\
(\mathrm{nNm})\end{array}$ & $\begin{array}{l}P_{\text {out }, d} \\
(\mu \mathrm{W})\end{array}$ & $\mu$ \\
\hline 224 & 12 & 20 & 10 & 66 & 5600 & 870 & 57 & 0.15 \\
\hline \multicolumn{9}{|c|}{ Electrical characteristics } \\
\hline $\begin{array}{l}U_{\text {in }} \\
\left(\mathrm{V}_{\mathrm{rms}}\right)\end{array}$ & $\begin{array}{l}I_{\mathrm{in}} \\
\left(\mathrm{mA}_{\mathrm{rms}}\right)\end{array}$ & $\begin{array}{l}\phi \\
(\mathrm{deg})\end{array}$ & $\begin{array}{l}P_{\text {in }} \\
(\mu \mathrm{W})\end{array}$ & $\begin{array}{l}P_{\text {loss }} \\
(\mu \mathrm{W})\end{array}$ & & & & \\
\hline 7 & 0.45 & 269 & 62 & 5.6 & & & & \\
\hline
\end{tabular}

lapped PZT plate. This manufacturing process was proved to work, although the yield of working stators in this prototype was only $20 \%$. Problems were mainly encountered in adhesive bonding and dicing. In bonding, the cymbal grid stuck onto the bonding tool or was not bonded onto the PZT plate. In dicing, some cymbals seemed to collapse. The possible reason for this may have been the water pressure in the dicing saw. With rotors, the bonding of the jewel onto the rotor was demanding. The cyanoacrylate adhesive spread out and control of the drop size was difficult. However, the methodology used here to manufacture 2-mm micro-motors of a relatively simple design is proven, and further development could undoubtedly solve the problems outlined above. With the help of modern robotics, the fin bending, bearing attachment, and final assembly can be made efficient and accurate. Based on the achieved experiences of the way to manufacture stator elements, the adaptation to series production should not be too difficult. The individual process steps are well known and, after the fine-tuning of the separate steps, such as etch time and electrode arrangements, the quality of the end product can be drastically improved.

The stall torque $(27 \mathrm{nNm})$ was evaluated from the fitted nonlinear representation of the acceleration. The transient characteristic was achieved from the recorded stream of images. The acceleration time constant and angle were $2850 \mathrm{~ms}$ and $43^{\circ}$, respectively. The first assumption based on the results from similar macro-motor suggested a factor-of-ten greater torque value should be achievable. The likely reason for the result achieved is the bearing configuration, which was here a jewel slide bearing. In macroscale, the ball bearing, in general, has a smaller frictional coefficient. Therefore, it would be interesting to run a test in a macro-scale with a jewel bearing or perhaps in a microscale with a ball bearing. The rotor/stator frictional coefficient 0.15 , evaluated based on the deceleration characteristics, is in accordance with the previous research where the same value was achieved for the $\mathrm{BeCu}-\mathrm{BeCu}$ interface [4]. This partly proves the reliability of the transient measurements. From the measurements reliability point-of-view, it was important to evaluate no-load speed with fiberoptic sensor and stroboscopic techniques. Results obtained from all three measurements gave practically the same reading.

The achieved maximum efficiency $(\sim 0.6 \%$, Fig. 14$)$ is close to that of other micro-motors using elastic-fin designs $(0.17 \%[20])$. In order to improve the efficiency, the stick/release found from high-speed images (see Figs. 12 and 13) should be analyzed in detail. Perhaps, an experiment similar to that with the macro-motor with different fin angles [7] could give answers for the optimal fin angle. Also, increasing the frictional coefficient with polymer coatings would improve the efficiency.

\section{REFERENCES}

[1] K. Uchino, Piezoelectric Actuators and Ultrasonic Motors. Boston, MA: Kluwer Academic, 1997.

[2] A. M. Flynn, L. S. Tavrow, S. F. Bart, R. A. Brooks, D. J. Ehrlich, K. R. Udayakumar, and L. E. Cross, "Piezoelectric micromotors for microrobots," in Proc. IEEE Ultrason. Symp., vol. 3, 1990, pp. 1163-1172.

[3] "Piezoelectric ceramic products UK," Morgan Matroc Ltd., Unilator Division, Wrexham, Clwyd, UK.

[4] P. Rayner, "Piezoelectric ultrasonic motors and micromotors," Ph.D. dissertation, Cranfield University, Canfield, Bedford, UK, 2000.

[5] T. Maeno, T. Tsukimoto, and A. Miyake, "Finite-element analysis of the rotor/stator contact in a ring-type ultrasonic motor," IEEE Trans. Ultrason., Ferroelect., Freq. Contr., vol. 39, pp. 668-674, 1992.

[6] K. Tani, M. Suzuki, T. Furuta, T. Sakuhara, and T. Ataka, "Development of a new type piezoelectric micromotor," in Proc. 11th Annu. Int. Workshop on MEMS, Heidelberg, Germany, 1998, pp. 396-401.

[7] J. T. Leinvuo, S. A. Wilson, and R. W. Whatmore, "Flextensional ultrasonic motor using the contour mode of a square piezoelectric plate," IEEE Trans. Ultrason., Ferroelect., Freq. Contr., vol. 51, no. 8, pp. 929-936, 2004.

[8] T. Uchiki, T. Nakazawa, K. Nakamura, M. Kurosawa, and S. Ueha, "Ultrasonic motor utilizing elastic fin rotor," Jpn. J. Appl. Phys., vol. 30, pp. 2289-2291, Sep. 1991.

[9] T. Sashida and T. Kenjo, An Introduction to Ultrasonic Motors. New York: Oxford Univ. Press, 1993.

[10] B. Jaffe, Jr., W. J. Cook, and H. Jaffe, Piezoelectric Ceramics. London: Academic Press, 1971.

[11] J. Leinvuo, "Flextensional piezoelectric motors," Ph.D. dissertation, Cranfield University, Cranfield, Bedford, UK, 2004. 
[12] T. Uchiki, T. Nakazawa, K. Nakamura, M. Kurosawa, and S. Ueha, "Ultrasonic motor utilizing elastic fin rotor," in Proc. IEEE Ultrason. Symp., 1991, pp. 929-931.

[13] "Sensors, vision systems \& measuring instruments, 20012002," G2001-UK-2-0700, Keyence (UK) Ltd., Milton Keynes, Buckinghamshire, UK.

[14] "The measurement and automation catalog, 2001," National Instruments Corporation (UK) Ltd., Newbury, Berkshire, UK.

[15] K. Nakamura, M. Kurosawa, H. Kurebayashi, and S. Ueha, "An estimation of load characteristics of an ultrasonic motor by measuring transient responses," IEEE Trans. Ultrason., Ferroelect., Freq. Contr., vol. 38, no. 5, pp. 481-485, 1991.

[16] J. T. Leinvuo, S. A. Wilson, R. W. Whatmore, and A. E. Gee, "Mesoscale piezo-motors: Scaling issues and performance measurement," presented at Proc. 17th Annu. ASPE Meeting, St. Louis, MO, 2002, CDROM.

[17] I. Fujimasa, Micromachines: A New Era in Mechanical Engineering. New York: Oxford Univ. Press, 1996.

[18] S. Dong, S. P. Lim, K. H. Lee, J. Zhang, L. C. Lim, and K. Uchino, "Piezoelectric ultrasonic micromotor with $1.5 \mathrm{~mm}$ diameter," IEEE Trans. Ultrason., Ferroelect., Freq. Contr., vol. 50, no. 4, pp. 361-367, Apr. 2003.

[19] Phantom V4.0 data sheet. Photo-Sonics International Ltd. Thame, Oxon, UK 2003.

[20] M. Dubois and P. Muralt, "PZT thin film actuated elastic fin micromotor," IEEE Trans. Ultrason., Ferroelect., Freq. Contr., vol. 45, pp. 1169-1177, Sep. 1998.

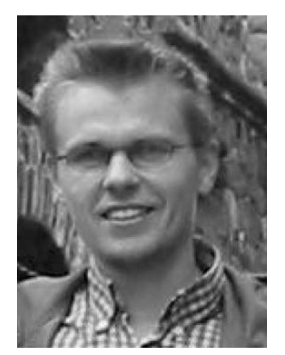

Joni T. Leinvuo was born in Helsinki, Finland, in April 1971. He received his M.S. degree in M.E. (Mechatronics) from Helsinki University of Technology in 2000 and his Ph.D. degree from Cranfield University, UK, in 2005 , for research related to piezoelectric motors and micro-motors. He currently holds a position at VTI Technologies, Finland, as a sensor design engineer related to microelectromechanical pressure sensors. His research interest includes piezoelectric motors, micromotors, and pressure sensors.

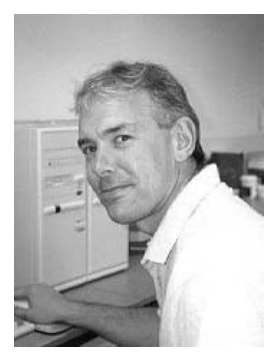

Stephen A. Wilson is a senior research fellow in Advanced Materials at Cranfield University, UK. He received a Ph.D. degree at Cranfield University for his thesis on "Electric Field Structuring of Piezoelectric Composites," which explored the use of moderately high electric fields during processing to induce anisotropic properties in ferroelectric ceramic/polymer composite materials. His study of materials processing parameters has been used to optimize the perfor- mance of piezoelectric sensor arrays for a real-time 3D ultrasound imaging system, and his research interests are in piezoelectric microactuators, ultraprecision machining of ceramics, and dielectrophoresis. He is a module coordinator and lectures on microsystems design.

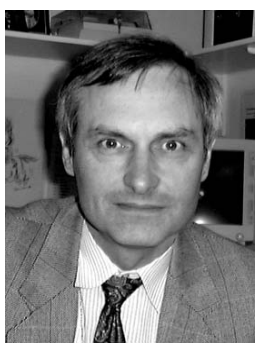

Roger W. Whatmore graduated with his Ph.D. degree from Cambridge University, UK, in 1977 , and spent nearly twenty years working with the GEC Marconi (formerly Plessey) Research Laboratories at Caswell in the UK on the development and exploitation of ferroelectric materials in a wide range of electronic devices, particularly sensors and actuators, for which work he was awarded GEC's Nelson Gold Medal in 1993. In October 1994, he took the Royal Academy of Engineering Chair in Engineering Nanotechnology at Cranfield University, where he is developing the use of ferroelectrics in microsystems and nanotechnology, particularly for sensors and actuators integrated onto silicon. He has published over 200 papers and has 30 patents in the field. He was awarded the degree of Doctor of Science by Cambridge University in 2001. He is a Fellow of the Royal Academy of Engineering and a Fellow of the Institute of Materials, Minerals and Mining, which in June 2003 awarded him its Griffith Medal and Prize for Distinguished Work in Materials Science.

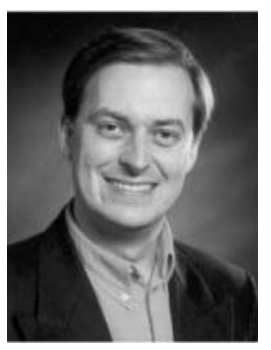

Markys G. Cain is a Principal Research Scientist at the National Physical Laboratory (NPL), UK, and runs the Functional Materials Research Group within the Division of Engineering and Process Materials. He is also their Knowledge Leader for Process Materials and oversees strategy development within Materials. He graduated from Warwick University with a B.Sc. degree in physics in 1986 and completed his Ph.D. degree, also at Warwick, in materials physics in 1989 . Following a twoyear postdoctoral appointment at the University of California, Santa Barbara's Materials Department, where he worked in developing process methods and models for epitaxial thin films, he returned to the UK as a Senior Research Fellow at Warwick University to start developing new characterization measurement methods for ceramic matrix composites with Rolls Royce and an SEM-based microindentation machine with Oxford Instruments. He joined NPL in 1997 and leads the Functional Materials Group in developing metrology and measurement good practice for piezoelectric bulk and thin film materials. He is author or co-author of over 90 publications in the fields of ceramic matrix composites, ferroelastic materials, the use of neutron and synchrotron radiation for in-situ materials characterization, and piezoelectric, ferroelectric, and pyroelectric bulk and thin film materials for integrated microsystems. 